GRANZOTTO, Eduardo; PERTILLE, Marcelo Bauer; PERTILLE, Thais Silveira. Externalidades na instalação de estabelecimentos prisionais nos municípios brasileiros: propostas legislativas para o atendimento do princípio da eficiência econômico-social. Revista Eletrônica Direito e Política, Programa de Pós-Graduação Stricto Sensu em Ciência Jurídica da UNIVALI, Itajaí, v.16, n.2, 20 quadrimestre de 2021. Disponível em: www.univali.br/direitoepolitica - ISSN 1980-7791.

\title{
EXTERNALIDADES NA INSTALAÇÃO DE ESTABELECIMENTOS PRISIONAIS NOS MUNICÍPIOS BRASILEIROS: PROPOSTAS LEGISLATIVAS PARA O ATENDIMENTO DO PRINCÍPIO DA EFICIÊNCIA ECONÔMICO-SOCIAL
}

\author{
EXTERNALITIES AND THE SETTLEMENT OF PENITENTIARY IN BRAZILIAN \\ MUNICIPALITIES: LEGISLATIVE PROPOSALS TO COMPLY WITH THE PRINCIPLE \\ OF ECONOMIC-SOCIAL EFFICIENCY
}

\author{
Eduardo Granzotto ${ }^{1}$ \\ Marcelo Bauer Pertille² \\ Thais Silveira Pertille ${ }^{3}$
}

\section{RESUMO}

O Brasil enfrenta um estado de coisas inconstitucional no que se refere às condições do sistema prisional brasileiro. Para contornar o problema, uma das medidas necessárias é construção de novas unidades penais. Porém, grande parte dos Municípios brasileiros se coloca como um entrave, diante das externalidades negativas acarretadas. Este estudo buscará responder se uma análise econômica do Direito, realizada a partir do princípio da eficiência econômico-social, pode contribuir para dissolução do impasse ocasionado entre a necessidade de aumento de vagas nos presídios e a resistência dos Municípios em recebê-los. Trata-se de pesquisa qualitativa exploratória, de procedimento monográfico, de abordagem dedutiva e técnica de pesquisa a bibliográfica.

\footnotetext{
1 Mestre em Paz e Segurança Internacional (Kings College London/Inglaterra). Especialista em Ciências Criminais e Processo Legislativo. Diplomado pela Escola Superior de Guerra (ESG) no curso Superior de Política e Estratégia (CSUPE). Consultor Legislativo da Câmara dos Deputados na área de Segurança Pública e Defesa Nacional. Advogado (OAB/DF). Lattes: http://lattes.cnpq.br/9355829869409713. ORCID: 0000-0002-7827-7363. E-mail: pinheirogranzotto@gmail.com

2 Doutorando e mestre em Ciências Criminais (PUCRS). Especialista em Direito Processual Penal (UNIVALI) e em Direito Público (UNIVALI). Professor de Direito Penal e Direitos Humanos. Advogado (OAB/SC). Lattes: http://lattes.cnpq.br/4560522200827508. ORCID: 0000-0003-0083450X. E-mail: marcelopertille@yahoo.com.br.

3 Doutoranda e mestra em Direito (UFSC). Especialista em Filosofia e Direitos Humanos (PUCPR). Pesquisadora do Observatório de Justiça Ecológica (UFSC-Grupo cadastrado no Cnpq). Professora de Direito Internacional e Direito Constitucional. Advogada (OAB/SC). Lattes: http://buscatextual.cnpq.br/buscatextual/visualizacv.do?id=K4049196E0. ORCID: 0000-00032939-8238. E-mail: thaispertille@gmail.com.
} 
GRANZOTTO, Eduardo; PERTILLE, Marcelo Bauer; PERTILLE, Thais Silveira. Externalidades na instalação de estabelecimentos prisionais nos municípios brasileiros: propostas legislativas para o atendimento do princípio da eficiência econômico-social. Revista Eletrônica Direito e Política, Programa de Pós-Graduação Stricto Sensu em Ciência Jurídica da UNIVALI, Itajaí, v.16, n.2, 20 quadrimestre de 2021. Disponível em: www.univali.br/direitoepolitica - ISSN 1980-7791.

Conclui por possíveis alterações legislativas que podem ser adotadas para que as externalidades negativas sejam minimizadas e/ou contornadas no sentido da concretização do princípio da eficiência econômico-social.

PALAVRAS-ChAVE: Crise prisional, Novos estabelecimentos penais e a recusa de municípios, princípio da Eficiência Econômico-Social, Análise econômica do Direito, Propostas legislativas.

\section{ABSTRACT}

Brazil is facing an unconstitutional state of affairs with regard to the conditions of the Brazilian prison system. To get around the problem, there is a need to build new penal units. However, a large part of Brazilian municipalities is an obstacle, given the negative externalities involved. This study will seek to answer whether an economic analysis of Law based on the principle of economic-social efficiency can contribute to dissolving the impasse caused between the need to increase spaces in prisons and the resistance of municipalities to receive them. It is an exploratory qualitative research, monographic procedure, deductive approach and bibliographic research technique. It concludes for possible legislative changes that can be adopted so that negative externalities are minimized or/and circumvented and the positive ones are sufficient to achieve economic and social efficiency.

KEY WORDS: Prison crisis, the settlement of penitentiary and the refusal of municipalities, principle of Economic-Social Efficiency, Economic Analysis of Law, Legislative proposals.

\section{INTRODUÇÃo}

O Brasil enfrenta, segundo levantamentos públicos ${ }^{4}$ e estudos científicos ${ }^{5}$, além da própria declaração do Supremo Tribunal Federal ${ }^{6}$, um estado de coisas inconstitucional no que se refere às condições do sistema prisional. Segundo recente relatório do Monitor da Violência7 (2021), a população carcerária no Brasil é de 682.182 internos. ${ }^{8}$ No entanto, conforme dados do Anuário de

4 BUENO, Samira; LIMA, Renato Sérgio (coord.). Anuário brasileiro de segurança pública. 2020. Disponível em: https://forumseguranca.org.br/wp-content/uploads/2020/10/anuario-142020-v1-interativo.pdf Acesso em 08.07.2021.

5 MAGALHÃES, Breno Baía. O Estado de coisas inconstitucional na ADPF 347 e a sedução do Direito: o impacto da medida cautelar e a resposta dos poderes políticos. Revista Direito GV, v. 15, n. 2, 2019, e1916. Doi: http://dx.doi.org/10.1590/2317-6172201916.

${ }^{6}$ BRASIL. Supremo Tribunal Federal. Arguição de Descumprimento de Preceito Fundamental n.

347/DF. Relator: ministro Marco Aurélio. Brasília, 9 de setembro de 2015.

7 Parceria entre o Portal G1, Núcleo de Estudos da Violência da USP e o Fórum Brasileiro de Segurança Pública.

8 G1. Monitor da violência. 2021. Disponível em: https://especiais.g1.globo.com/monitor-daviolencia/2021/raio-x-do-sistema-prisional/ Acesso em: 09/07/2021 
GRANZOTTO, Eduardo; PERTILLE, Marcelo Bauer; PERTILLE, Thais Silveira. Externalidades na instalação de estabelecimentos prisionais nos municípios brasileiros: propostas legislativas para o atendimento do princípio da eficiência econômico-social. Revista Eletrônica Direito e Política, Programa de Pós-Graduação Stricto Sensu em Ciência Jurídica da UNIVALI, Itajaí, v.16, n.2, $2^{\circ}$ quadrimestre de 2021. Disponível em: www.univali.br/direitoepolitica - ISSN 1980-7791.

Segurança Pública (2020), só há 449.614 vagas disponíveis no sistema, o que representa um déficit que gira em torno de duzentas e trinta mil. ${ }^{9}$

A solução para esse problema passa por uma série de discussões, que vão desde reflexões sobre práticas operacionais no âmbito da segurança pública, reformas legais (também suas sistematizações teóricas) e cultura do encarceramento ${ }^{10}$, até projetos para a construção de novos estabelecimentos penais.

Quando o assunto recai sobre a edificação de novas unidades penitenciárias, grande parte das administrações municipais no Brasil se coloca em oposição. Como fundamento, são suscitadas dúvidas acerca dos impactos econômicos e sociais que essas construções podem causar às suas realidades diárias.

E aqui reside o foco deste estudo, diante do que se pretende enfrentar a questão a partir de contribuições que uma análise econômica do direito pode oferecer na esteira do primado da eficiência econômico-social. Daí que os possíveis impactos dessas construções para os Municípios brasileiros serão abordados enquanto externalidades positivas e negativas.

Cabe a ressalva, entretanto, de que não se pode perder de vista que cada realidade administrativa tem suas peculiaridades geográfica e social, que representam características próprias e inafastáveis nos processos de tomada de decisões. Por isso, a intenção das ideias trabalhadas neste artigo reside fundamentalmente na análise de um contexto geral. Serão levados em conta motivos que podem auxiliar no convencimento das administrações municipais de que um estabelecimento penitenciário em seus domínios pode também representar possibilidades de crescimento.

O objetivo, assim, é delinear como as consequências negativas podem ser minimizadas, mediante estudos de impacto de vizinhança, assim como incentivos de cunho financeiro àquelas cidades que voluntariamente aceitem receber unidades prisionais em seus territórios. Para tanto, também se considerará o

\footnotetext{
9 BUENO, Samira; LIMA, Renato Sérgio (coord.). Anuário brasileiro de segurança pública. p. 283.

10 ANDRADE, Vera Regina. A ilusão de segurança jurídica: do controle da violência à violência do controle. Livraria do Advogado: Porto Alegre, 1997.
} 
GRANZOTTO, Eduardo; PERTILLE, Marcelo Bauer; PERTILLE, Thais Silveira. Externalidades na instalação de estabelecimentos prisionais nos municípios brasileiros: propostas legislativas para o atendimento do princípio da eficiência econômico-social. Revista Eletrônica Direito e Política, Programa de Pós-Graduação Stricto Sensu em Ciência Jurídica da UNIVALI, Itajaí, v.16, n.2, 20 quadrimestre de 2021. Disponível em: www.univali.br/direitoepolitica - ISSN 1980-7791.

tema sob a hipótese de que alterações legislativas podem colaborar com o cenário em exame.

Acerca da metodologia, vale destacar que há uma limitação bibliográfica envolvida em pesquisas dessa natureza. Não há publicação suficiente de dados, análises ou estudos por órgãos governamentais sobre o assunto. As fontes, ainda tímidas, sobre consequências aos Municípios pela implantação de unidades prisionais são fruto, em geral, de trabalhos acadêmicos.

Assim, considerando tais limitações, o referencial teórico deste artigo tem como base cinco publicações: a) "Estudo de Impacto de Vizinhança e a Construção de Novos Estabelecimentos Penais: Delineando uma Relação"11; b) "Impactos Sociais e Ambientais Sofridos nos Municípios com Presídios, bem como Alternativas de Contrapartida do Estado para esses Municípios"12; c) "O Rastro da Indústria Penal: A Interiorização Penitenciária e Novo Paradigma dos Municípios Paulistas"13; d) "Contribuição ao Estudo dos Dilemas e Impactos das Unidades Prisionais do Pontal do Paranapanema: um Estudo de Caso do Município de Marabá"14; e e) "Cidades Carcerárias: Migração e Presídios em Regiões de São Paulo"15.

No intuito de melhor delinear do tema, o presente estudo pretende colaborar para a resposta do seguinte problema: a análise econômica do Direito, realizada

11 NASCIMENTO, Raul Victor Rodrigues do. Estudo de Impacto de Vizinhança e a Construção de Novos Estabelecimentos Penais: delineando uma relação. Revista Transgressões: Ciências Criminais em Debate, v.4, n.1, Maio 2016. Disponível em:https://periodicos.ufrn.br/transgressoes/article/view/9477/6843, acesso em 27.3.2021.

12 MENDES, Tânia R.. Impactos sociais e ambientais sofridos nos municípios com presídios, bem como alternativas de contrapartida do Estado para esses Municípios. Biblioteca Digital da Assembleia Legislativa de São Paulo. Disponível em: https://www.al.sp.gov.br/repositorio/bibliotecaDigital/377_arquivo.pdf, acessado em 27.3.2021. 13 SILVESTRE, Giane. O rastro da Indústria Penal: A Interiorização Penitenciária e novo paradigma dos Municípios paulistas. Revista do Laboratório de Estudos da Violência e Segurança Levis, n.1 (2008). Disponível em: http://www2.marilia.unesp.br/revistas/index.php/levs/article/view/767, acesso em 27.3.2021

14 FERREIRA, Silvia Aline Silva. Contribuição ao Estudo dos Dilemas e Impactos das Unidades Prisionais do Pontal do Paranapanema: um Estudo de Caso do Município de Marabá. Tese de Mestrado defendida em 7.12.2017, na Universidade do Oeste Paulista - UNOESTE. Disponível em: http://bdtd.unoeste.br:8080/jspui/handle/jspui/1075, acesso em 27.3.2021.

${ }^{15}$ CESCON, Flávia R. P.; BAENINGER, Rosana. Cidades Carcerárias: Migração e Presídios em Regiões de São Paulo Trabalho apresentado no XVII Encontro Nacional de Estudos Populacionais, realizado em Caxambu - MG - Brasil, de 20 a 24 de setembro de 2010. Disponível em: http://www.abep.org.br/ abeporgb/publicacoes/index.php/anais/article/viewFile/2328/2282, acesso em 27.3.2021. 
GRANZOTTO, Eduardo; PERTILLE, Marcelo Bauer; PERTILLE, Thais Silveira. Externalidades na instalação de estabelecimentos prisionais nos municípios brasileiros: propostas legislativas para o atendimento do princípio da eficiência econômico-social. Revista Eletrônica Direito e Política, Programa de Pós-Graduação Stricto Sensu em Ciência Jurídica da UNIVALI, Itajaí, v.16, n.2, $2^{\circ}$ quadrimestre de 2021. Disponível em: www.univali.br/direitoepolitica - ISSN 1980-7791.

a partir do princípio da eficiência econômico-social, pode contribuir para dissolução do impasse ocasionado entre a necessidade de aumento de vagas no sistema penitenciário brasileiro e a resistência dos Municípios em recebê-los?

Para tanto, o artigo utiliza metodologia de pesquisa qualitativa exploratória, de procedimento monográfico, de abordagem dedutiva e técnica de pesquisa bibliográfica, e está dividido em três partes. A primeira trará dados do sistema prisional brasileiro, a fim de contextualizar generalidades do cenário que se pretende considerar. A segunda abordará os eventuais impactos positivos e negativos para os Municípios brasileiros diante da instalação de casas penais, elencando as externalidades que podem ser valoradas na busca pela concretização do princípio da eficiência econômico-social. A terceira parte considerará a hipótese de que com adaptações legislativas é possível minimizar os impactos negativos e incentivar os Municípios a receberem unidades penais em suas regiões.

\section{ELEMENTOS SOBRE A SITUAÇÃO GERAL DO SISTEMA PRISIONAL NO} BRASIL

A situação do sistema prisional brasileiro já foi criticada pelos mais diversos setores da sociedade diante de seus diferentes déficits no cumprimento dos fins das penas e na adequação às normas básicas de Direitos Humanos. As violações são tantas que o encarceramento no Brasil faz com que as pessoas privadas de liberdade passem a integrar grupos vulneráveis para diversos outros problemas.

Esses, em contexto geral, resumem-se na falta de condições materiais e humanas para o implemento de exigências da Lei de Execução Penal (7.210/84). Dentre as principais consequências, precariza-se a prevenção específica, com consequente aumento da taxa de reincidência, diante da falta de condições para a viabilidade de um futuro profissional (também pessoal) extramuros. Tal quadro colabora até mesmo para uma maior capacidade organizacional de grupo criminosos que se estabelecem no interior do sistema penitenciário e que agem cotidianamente na cooptação de novos membros, articulando variadas formas de ações delituosas. 
GRANZOTTO, Eduardo; PERTILLE, Marcelo Bauer; PERTILLE, Thais Silveira. Externalidades na instalação de estabelecimentos prisionais nos municípios brasileiros: propostas legislativas para o atendimento do princípio da eficiência econômico-social. Revista Eletrônica Direito e Política, Programa de Pós-Graduação Stricto Sensu em Ciência Jurídica da UNIVALI, Itajaí, v.16, n.2, 20 quadrimestre de 2021. Disponível em: www.univali.br/direitoepolitica - ISSN 1980-7791.

Em contexto específico, situações como a da atual pandemia de Covid-19 demonstram ainda mais as dificuldades diárias das administrações prisionais no país. Tamanha é a preocupação que a Organização das Nações Unidas já concluiu que "Problemas estruturais preexistentes, tais como superlotação crônica e condições anti-higiênicas, aliados à falta de acesso adequado à saúde, possibilitaram a rápida disseminação da COVID-19 "16.

À luz desse cenário, em 2015, o Supremo Tribunal Federal (STF) reconheceu um Estado de Coisas Inconstitucional $(E C I)^{17}$ do sistema penitenciário brasileiro. Com as palavras do Tribunal é possível dimensionar a gravidade do tema: "um quadro de violação generalizada e sistêmica de direitos fundamentais, causado pela inércia ou incapacidade reiterada e persistente das autoridades públicas em modificar a conjuntura"18. E mais, indicou a Corte que "apenas transformações estruturais da atuação do Poder Público e a atuação de uma pluralidade de autoridades podem alterar a situação inconstitucional"19.

Assim sendo, dessa premente necessidade de pensar ações e efetuar reformas é que este estudo se origina. E no centro da preocupação está a superlotação das casas penais brasileiras, ponto decisivo para tantas violações e que, se contornado, pode capitanear uma série de mudanças indispensáveis. Isso em razão de que se mostra incongruente imaginar um sistema de execução penal capaz de fruir direitos e deveres básicos das pessoas presas em ambientes sem capacidade física mínima para abrigar o número de condenados existente.

\footnotetext{
16 CÂMARA DOS DEPUTADOS. ONU faz alerta sobre presídios no Brasil e apoia desencarceramento por causa da pandemia; presidente da CDHM endossou iniciativa em março. 2020. Disponível em: https://www2.camara.leg.br/atividade-legislativa/comissoes/comissoespermanentes/cdhm/noticias/onu-faz-alerta-sobre-presidios-no-brasil-e-apoia-desencarceramentopor-causa-da-pandemia-presidente-da-cdhm-endossou-iniciativa-em-marco Acesso em: 09/07/2021.

17 BRASIL. Supremo Tribunal Federal. Arguição de Descumprimento de Preceito Fundamental n. 347/DF.

18 BRASIL. Supremo Tribunal Federal. Arguição de Descumprimento de Preceito Fundamental n. 347/DF.

${ }^{19}$ BRASIL. Supremo Tribunal Federal. Arguição de Descumprimento de Preceito Fundamental n. 347/DF.
} 
GRANZOTTO, Eduardo; PERTILLE, Marcelo Bauer; PERTILLE, Thais Silveira. Externalidades na instalação de estabelecimentos prisionais nos municípios brasileiros: propostas legislativas para o atendimento do princípio da eficiência econômico-social. Revista Eletrônica Direito e Política, Programa de Pós-Graduação Stricto Sensu em Ciência Jurídica da UNIVALI, Itajaí, v.16, n.2, 20 quadrimestre de 2021. Disponível em: www.univali.br/direitoepolitica - ISSN 1980-7791.

De acordo com o último relatório do Monitor da Violência20 (2021), a população carcerária no Brasil é de 682.182 pessoas. ${ }^{21}$ Embora o estudo revele uma queda desde 2014, o que também se deu em decorrência da criação de novos espaços, o déficit ainda é alto, alcançando algo perto de duzentas e trinta mil vagas. Essa realidade, vale sublinhar, mantém o país entre os que mais encarceram no mundo em números absolutos. ${ }^{22}$

No ano 2000, a população carcerária no Brasil era de 232.755 presos e, no ano de 2019, atingiu 755.274, configurando-se aqui um aumento de 224,5\%. ${ }^{23}$ Para melhor visualizar a evolução, segue, na íntegra, gráfico publicado pelo Anuário Brasileiro de Segurança Pública: ${ }^{24}$

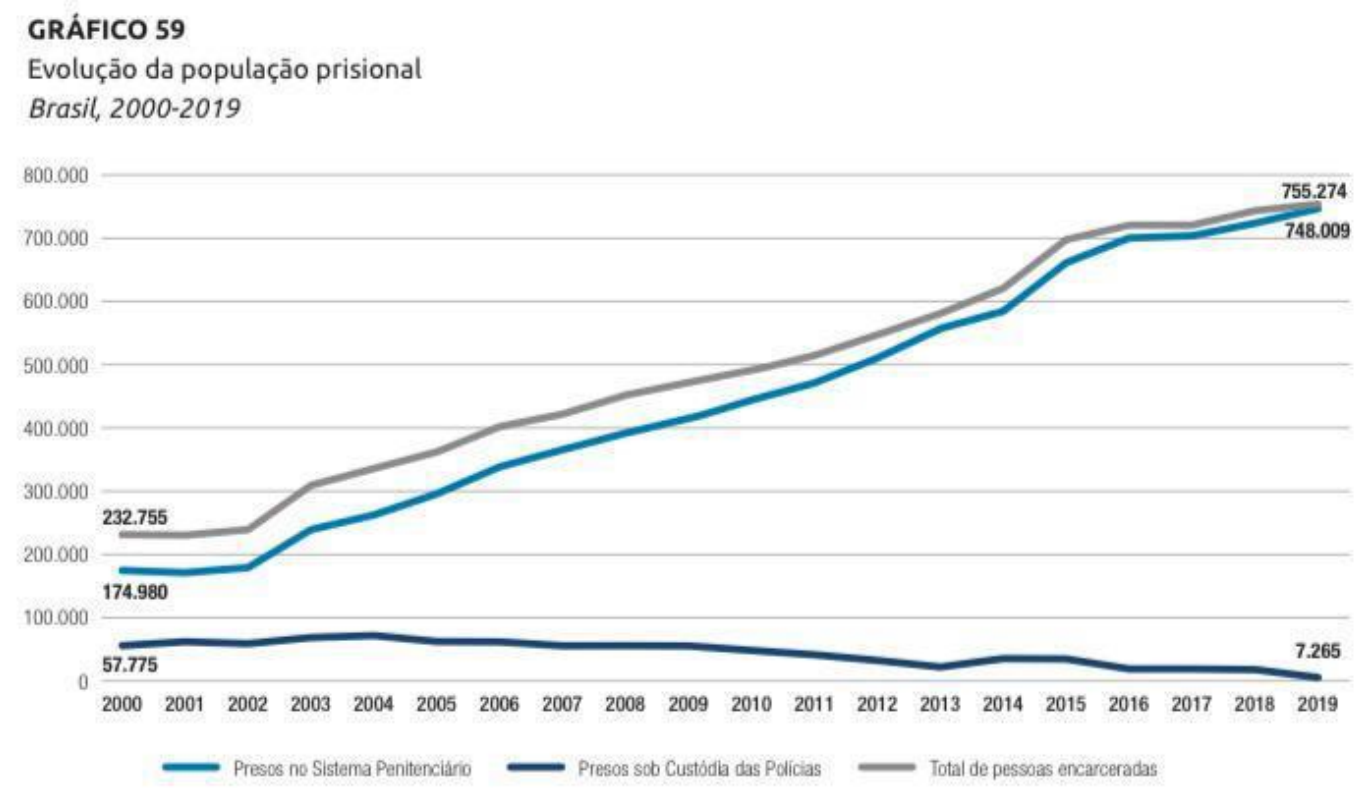

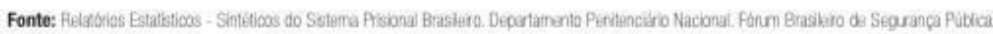

Essa espiral de crescimento tem pressionado a União e os Estados para a criação de novas vagas. Há clara necessidade da construção de estabelecimentos

20 Parceria entre o Portal G1, Núcleo de Estudos da Violência da USP e o Fórum Brasileiro de Segurança Pública.

${ }^{21}$ G1. Monitor da Violência.

22 BUENO, Samira; LIMA, Renato Sérgio (coord.). Anuário brasileiro de segurança pública. p. 86.

${ }^{23}$ BUENO, Samira; LIMA, Renato Sérgio (coord.). Anuário brasileiro de segurança pública. p. 290-291.

${ }^{24}$ BUENO, Samira; LIMA, Renato Sérgio (coord.). Anuário brasileiro de segurança pública. $\mathrm{p}$. 292. 
GRANZOTTO, Eduardo; PERTILLE, Marcelo Bauer; PERTILLE, Thais Silveira. Externalidades na instalação de estabelecimentos prisionais nos municípios brasileiros: propostas legislativas para o atendimento do princípio da eficiência econômico-social. Revista Eletrônica Direito e Política, Programa de Pós-Graduação Stricto Sensu em Ciência Jurídica da UNIVALI, Itajaí, v.16, n.2, 20 quadrimestre de 2021. Disponível em: www.univali.br/direitoepolitica - ISSN 1980-7791.

capazes de abrigar presos em diferentes regimes de cumprimento de penas e medidas de segurança (penitenciárias, colônias agrícolas e industriais, albergues e hospitais de custódia). Segundo informações do Conselho Nacional de Justiça CNJ, pelo sistema Geopresídios, há 2.853 estabelecimentos penais ativos no país ${ }^{25}$, o que, na esteira dos dados anteriores, não atende a demanda nacional.

Um dos vários dilemas que envolvem a construção de novas unidades penais é a escolha do local. Embora a responsabilidade pela criação de novas vagas seja da União e, principalmente, dos Estados, quem acaba sofrendo os maiores impactos com a implementação dessas estruturas são os Municípios.

Assim, fundamental analisar os argumentos que corriqueiramente são invocados como justificativas para recusas.

\section{2. externalidades positivas e negativas pela instalação de ESTABELECIMENTOS PENAIS NO ÂMBITO DOS MUNICÍPIOS}

De início, ressalta-se que a lógica argumentativa se dará por meio da análise econômica do Direito, vertente cujo horizonte hermenêutico parte do manejo de recursos para justificar o comportamento de indivíduos e instituições diante da busca por resultados eficientes. ${ }^{26}$ A lógica que ocupa o centro das avaliações dessa natureza parte da condição de que as demandas são infinitas, embora os recursos sejam limitados, quando respostas precisam ser avaliadas diante dessa interação estrutural.

Os problemas que constituem a razão dessa vertente de pensamento, portanto, estão em promover a otimização dos meios de modo que possam cumprir seu papel perante objetivos preestabelecidos. Trata-se de pensar soluções capazes de, com os meios disponíveis, chegar mais perto daquilo desejado. E é essa a dialética que pode ser muitas vezes útil ao Direito na medida em que propõe o

\footnotetext{
25 CNJ. Sítio eletrônico do Geopresídios. 2021. Disponível em: https://www.cnj.jus.br/inspecao_penal/mapa.php, acessado em 27.3.2021.

26 ALVAREZ, Alejandro. Análise Econômica do Direito: contribuições e desmistificações. Disponível em: <http://direitoestadosociedade.jur.puc-rio.br/media/Bugallo_n29.pdf> Acesso em: 4 junho. 2021.
} 
GRANZOTTO, Eduardo; PERTILLE, Marcelo Bauer; PERTILLE, Thais Silveira. Externalidades na instalação de estabelecimentos prisionais nos municípios brasileiros: propostas legislativas para o atendimento do princípio da eficiência econômico-social. Revista Eletrônica Direito e Política, Programa de Pós-Graduação Stricto Sensu em Ciência Jurídica da UNIVALI, Itajaí, v.16, n.2, 20 quadrimestre de 2021. Disponível em: www.univali.br/direitoepolitica - ISSN 1980-7791.

estabelecimento de padrões capazes de racionalizar a escolha das determinações legislativas, por exemplo.

Portanto, essencial esclarecer o conceito de externalidade no âmbito das análises econômicas do direito. Serão aqui consideradas como os efeitos gerados a terceiros não envolvidos diretamente no processo de tomada de decisões. ${ }^{27}$ Exemplificando, pode-se imaginar uma relação entre $A$ e $B$, em que ambos tomam decisões conscientes sobre o que desejam acordar: as externalidades compreendem-se nas consequências positivas e/ou negativas que a relação entre A e B vão gerar para $C$, quem não teve gerência alguma sobre as condições do convencionado.

A externalidade é considerada negativa quando decisões de produção e de consumo afetam a disponibilidade dos serviços e/ou reduzem o bem-estar ou a satisfação de outros interesses envolvidos. ${ }^{28}$ Importante advertir que sem parâmetros que possam indicar o desequilíbrio nessas relações a quantidade de externalidade produzida por um agente não alcançará um ponto eficiente ${ }^{29}$, capaz de oferecer condições de contorno. Pontos de equilíbrio devem ser entendidos como a definição de processos de tomada de decisões a partir do conhecimento das reais condições capazes de exercer influência para os acordantes e para terceiros indiretamente envolvidos.

É a partir do ponto de equilíbrio que se podem reconhecer vantagens desproporcionais (e até ilícitas) ou desvantagens capazes de influenciar a esfera econômica e/ou de direitos daqueles abrangidos. O custo social que as externalidades podem produzir sequer poderá ser levado em conta pelos agentes

\footnotetext{
27 Explica-se que os custos sociais correspondem a todos os custos diretos e indiretos que uma atividade gera. Envolvendo os que não são suportados pelos agentes diretos da relação, inclusive: "Quando não há consciência e/ou aceitação das parcelas de custo, apresenta-se o fenômeno de geração de custos externos, também chamado de externalidade". Ver mais em: MARTINS, Paulo Matos. Externalidades e custos externos: alguns conceitos quanto à sua avaliação e internalização no sector dos transportes. DEC/ISEL. 2004.

28 WEYDMANN, Celso Leonardo. Externalidades e mudanças da regulamentação ambiental para a suinocultura norte-americana: é possível no caso brasileiro? Revista de Economia e Sociologia Rural [online]. 2005, v. 43, n. 2. Acesso: 9/07/2021. pp. 287-305.

${ }^{29}$ Aqui cabe o conceito de "ótimo de Pareto" pelo qual os recursos encontram a melhor alocação possível em uma relação gerando um equilíbrio.
} 
GRANZOTTO, Eduardo; PERTILLE, Marcelo Bauer; PERTILLE, Thais Silveira. Externalidades na instalação de estabelecimentos prisionais nos municípios brasileiros: propostas legislativas para o atendimento do princípio da eficiência econômico-social. Revista Eletrônica Direito e Política, Programa de Pós-Graduação Stricto Sensu em Ciência Jurídica da UNIVALI, Itajaí, v.16, n.2, 20 quadrimestre de 2021. Disponível em: www.univali.br/direitoepolitica - ISSN 1980-7791.

nas decisões quando desconhecido o ponto de equilíbrio. O desequilíbrio, por sua vez, deve ser entendido como falha de mercado.

Daí a importância de análises econômicas que possam contribuir com soluções jurídicas, quando são criadas melhores condições para se identificar e ressarcir direitos afetados pelas externalidades. Assim é que se pode agir juridicamente na prevenção de danos e na delimitação de eventuais responsabilidades. Havendo falha de mercado, "o Estado pode intervir na tentativa de correção da externalidade, sendo comum a incidência de imposto e ou a fixação de limites". ${ }^{30}$

Aqui, pretende-se identificar os impactos sentidos pelos Municípios que recepcionam estruturas do sistema prisional como exemplo de externalidades. Propõe-se compreender em que medida podem ser consideradas em um contexto global para que seja possível, diante de compensações, insistir na construção de novas casas penais sob a justificativa de efetivar o princípio da eficiência econômico-social.

Análises econômicas do Direito têm sido cada vezes mais comuns, pois muitos economistas e juristas debruçam-se sobre a relação econômico-jurídica e sua capacidade de criar e lidar com as externalidades. Importante citar aquele que é tido como o idealizador de muitos dos paradigmas hoje seguidos: Ronald Coase foi quem desenvolveu grande parte das bases teóricas que relacionaram a otimização de recursos com o tratamento das externalidades.

Apesar da revolução que proporcionou, o Teorema de Coase ${ }^{31}$ não reúne condições para ser aplicado aqui diante das limitações estabelecidas pelo próprio autor, uma vez que mira relações entre particulares. A questão dos sistemas penitenciários, entretanto, manifesta-se diretamente no âmbito dos temas de Estado.

Ciente disso, repisa-se que não há quantidade necessária de estudos públicos feitos por órgãos governamentais a respeito dos impactos causados aos

30 WEYDMANN, Celso Leonardo. Externalidades e mudanças da regulamentação ambiental para a suinocultura norte-americana: é possível no caso brasileiro? pp. 287-305.

31 COASE, Ronald. O problema do custo social. The Latin American and Caribbean Journal of Legal Studies. Volume 3, Issue 1. Article 9. University of Chicago. 2008. 
GRANZOTTO, Eduardo; PERTILLE, Marcelo Bauer; PERTILLE, Thais Silveira. Externalidades na instalação de estabelecimentos prisionais nos municípios brasileiros: propostas legislativas para o atendimento do princípio da eficiência econômico-social. Revista Eletrônica Direito e Política, Programa de Pós-Graduação Stricto Sensu em Ciência Jurídica da UNIVALI, Itajaí, v.16, n.2, 20 quadrimestre de 2021. Disponível em: www.univali.br/direitoepolitica - ISSN 1980-7791.

Municípios com a implantação de estabelecimentos penais. O empenho em identificar essas consequências tem se concentrado precipuamente no ambiente acadêmico. Nesse contexto, o estudo de Raul Victor do Nascimento evidencia:

[...] os impactos das unidades prisionais não são limitados aos apenados reclusos em sua carceragem - elas abarcam, direta e indiretamente, um grande número de pessoas, na qualidade dos familiares e visitantes dos apenados que constantemente se dirigem aos estabelecimentos penais, na qualidade de agentes penitenciários e funcionários das unidades prisionais, na qualidade de comerciantes e fornecedores que oferecem seus produtos e serviços para aqueles que mantêm relações diretas e indiretas com os presídios, e na qualidade daqueles que vivem nos entornos dos presídios.

$[\ldots]$

[...] Uma prisão, em teoria, acumula e desempenha as atividades naturais ao funcionamento de escola, oficina, indústria ou local de trabalho, centro de saúde e templo religioso, sem esquecer as próprias funções inerentes à manutenção da vida de centenas de seres humanos. ${ }^{32}$

Destarte, são os Municípios que enfrentam essas externalidades, haja vista que se revestem de impactos locais. Contudo, é importante lembrar que uma mesma variável pode ter impacto positivo em um Município e negativo em outro. Tudo a depender de aspectos culturais do local, e principalmente do planejamento para a construção da unidade e dos recursos empregados.

Passa-se agora a evidenciar uma relação não exaustiva de eventuais externalidades. Como possível externalidade positiva, a melhoria da economia local é realidade que deve ser considerada. A instalação de unidades penais pode estimular a economia do Município uma vez que os estabelecimentos prisionais movimentam boa parte da estrutura a sua volta, com a criação de empregos diretos e indiretos.

Serviços que envolvem os próprios detentos (alimentação, produtos de higiene, contratação de advogados etc.), além daqueles necessários para o atendimento

\footnotetext{
32 NASCIMENTO, Raul Victor Rodrigues do. Estudo de Impacto de Vizinhança e a Construção
} de Novos Estabelecimentos Penais: delineando uma relação. p. 162. 
GRANZOTTO, Eduardo; PERTILLE, Marcelo Bauer; PERTILLE, Thais Silveira. Externalidades na instalação de estabelecimentos prisionais nos municípios brasileiros: propostas legislativas para o atendimento do princípio da eficiência econômico-social. Revista Eletrônica Direito e Política, Programa de Pós-Graduação Stricto Sensu em Ciência Jurídica da UNIVALI, Itajaí, v.16, n.2, 20 quadrimestre de 2021. Disponível em: www.univali.br/direitoepolitica - ISSN 1980-7791.

dos familiares visitantes e funcionários (hotéis, meios de transporte, restaurantes, farmácias, etc.) movimentam a economia local. Em meio à estagnação econômica vivida por muitos Municípios brasileiros ${ }^{33}$, a criação de unidades penais pode representar um estímulo. O exemplo trazido por Flávia Cescon e Rosana Baeninger, no município de Pacaembu, após a instalação de uma unidade prisional na localidade, ilustra essa perspectiva:

O número de taxistas praticamente triplicou. É vasto também o número de pessoas que prestam serviços de transporte informal aos visitantes para obter uma renda extra; $O$ hotel mais antigo da cidade encontra-se superlotado aos finais de semana, em decorrência, aproveitando-se desta demanda, alguns moradores do município oferecem serviços de hospedagem com alimentação ou abriram pensões na informalidade; Um dos dois supermercados do município permanece de portas abertas aos Sábados até às 18 horas e aos domingos até as 12 horas (o horário normal do comércio municipal é de Sábado até as 12 horas e aos Domingos os estabelecimentos não abrem); O valor do aluguel das casas está em alta, subindo consideravelmente nos últimos anos, porém em decorrência da grande procura (familiares dos detentos e de funcionários dos presídios) não se encontra mais casas de aluguel no município; $[\ldots]^{34}$

No âmbito financeiro do Município, pode-se elencar como externalidade positiva o aumento de arrecadação: em algumas situações, o aumento populacional causado pela instalação da unidade penal (não só por causa do número de apenados, mas também por conta do número dos funcionários e dos familiares que se mudam para ficarem mais perto de seus entes) altera o coeficiente de arrecadação do Fundo de Participação do Município (FPM). Ou seja, a depender do tamanho do aumento populacional, o Município pode ser beneficiado com o acréscimo da arrecadação, por meio do FPM.

Exemplo disso encontra-se no município do Tupi Paulista, no Estado de São Paulo, que contava com população de 13.000 habitantes antes da instalação de uma unidade prisional em seu território, o que possibilitava arrecadação no

\footnotetext{
33 MARIANO, Jeferson; BARCELLOS, Lívia. As estratégias de gestão dos municípios brasileiros em cenário de crise econômica. Élisée, Rev. Geo. UEG - Porangatu, v.5, n.2, p.45-58, jul./dez. 2016. ${ }^{34}$ CESCON, Flávia R. P.; BAENINGER, Rosana. Cidades Carcerárias: Migração e Presídios em Regiões de São Paulo. p. 9.
} 
GRANZOTTO, Eduardo; PERTILLE, Marcelo Bauer; PERTILLE, Thais Silveira. Externalidades na instalação de estabelecimentos prisionais nos municípios brasileiros: propostas legislativas para o atendimento do princípio da eficiência econômico-social. Revista Eletrônica Direito e Política, Programa de Pós-Graduação Stricto Sensu em Ciência Jurídica da UNIVALI, Itajaí, v.16, n.2, $2^{\circ}$ quadrimestre de 2021. Disponível em: www.univali.br/direitoepolitica - ISSN 1980-7791.

coeficiente do FPM de 0,8\% (cerca de 400 mil reais). Com a construção do presídio, a população cresceu e permitiu que o município passasse a receber dentro do coeficiente de $1 \%$, aumentando a arrecadação para cerca 500 mil reais. ${ }^{35}$

De outro norte, externalidades negativas também podem ser diagnosticadas e pensadas para que sejam contornadas. Elas se dão principalmente no contexto da sensação de insegurança gerada. Esse é um dos principais pontos de resistência por parte das administrações e populações locais. Vários são os fatores considerados aqui. O preconceito e o estigma social em relação aos apenados é muito grande no Brasil. Segundo o Anuário Brasileiro de Segurança Pública, $57 \%$ da população brasileira concorda com a frase "bandido bom é bandido morto"36. Além disso, a população local passa a conviver com as famílias e com os visitantes dos presos, o que, também por preconceitos, causa medo nos habitantes locais.

Assim, o simples fato de haver uma casa penal no Município já se mostra capaz de abalar a sensação de segurança em muitas comunidades. A desinformação também contribui para esse cenário. Mesmo que o número de fugas e de rebeliões seja pequeno o receio por esses eventos gera não receptibilidade das instituições. Dados do relatório Sistema Prisional em Números mostra que, tendo em conta o ano-base 2019, o número de fugas nos estabelecimentos penais brasileiros foi de 6.327 , o que, levando em consideração a população carcerária de 720.200 de pessoas presas a época, aponta índice de 0,88\%. ${ }^{37}$

Entretanto, há que se considerar ainda situações em que os índices de criminalidade de fato aumentam em municípios que passam a contar com penitenciárias, quando se vê superada a noção meramente abstrata de sensação de insegurança. Essa realidade pode ser explicada, em contexto geral, levando-

35 CESCON, Flávia R. P.; BAENINGER, Rosana. Cidades Carcerárias: Migração e Presídios em Regiões de São Paulo. p. 11.

36 AGÊNCIA SENADO. Desconfiança e preconceito da sociedade dificultam ressocialização de presos. 2017. Disponível em: https://www12.senado.leg.br/noticias/especiais/especialcidadania/desconfianca-e-preconceito-da-sociedade-dificultam-ressocializacao-de-presos Acesso em: 09/07/2021.

37 CONSELHO NACIONAL DO MinistéRIO PÚBLICO. Sistema Prisional em Números. 2020. Disponível em: https://www.cnmp.mp.br/portal/relatoriosbi/sistema-prisional-em-numeros. Acesso em: $12 / 07 / 2021$. 
GRANZOTTO, Eduardo; PERTILLE, Marcelo Bauer; PERTILLE, Thais Silveira. Externalidades na instalação de estabelecimentos prisionais nos municípios brasileiros: propostas legislativas para o atendimento do princípio da eficiência econômico-social. Revista Eletrônica Direito e Política, Programa de Pós-Graduação Stricto Sensu em Ciência Jurídica da UNIVALI, Itajaí, v.16, n.2, 20 quadrimestre de 2021. Disponível em: www.univali.br/direitoepolitica - ISSN 1980-7791.

se em conta que o aumento do fluxo de pessoas estranhas ao local promove maior interação de vontades e necessidades. Natural que em um cenário mais populoso haja mais condutas penalmente típicas e conflitos variados. ${ }^{38}$

A questão social muitas vezes se agrava, tendo em vista que a maioria dos familiares que se mudam para a cidade em que está localizada a unidade prisional é de baixa renda. Cria-se uma rede de serviços informais que acaba por sobrecarregar os serviços públicos locais, como escolas, hospitais e segurança púbica. Em pesquisa de campo, Silvia Aline da Silva concluiu que há:

[...] impactos sociais gerados por um choque de cultura entre os munícipes, familiares visitantes e também das famílias dos sentenciados que residem nos Municípios.

[...] as unidades prisionais são territórios de vivências que apresentam dinâmicas próprias de funcionamento, fechados em seu cotidiano, com regras e relações conflituosas entre os sentenciados e entre os sentenciados e agentes administrativos e sociais da unidade. Esses conflitos são revelados apenas em momentos de motim e rebeliões.

[...] Os entrevistados apontaram aumento das questões sociais, como pobreza, o aumento do tráfico de drogas, a precariedade social com que as famílias se deslocam de seus Municípios de origem e migram para ficarem mais próximas dos sentenciados e facilitar as visitas. Frente a essa realidade é fundamental o investimento em políticas públicas que atendam às necessidades sociais apresentadas por essas famílias, como amparo material, orientações acerca dos serviços mínimos de saúde, educação e moradia. A política de segurança pública é afetada com o aumento do tráfico de drogas, além do sistema de garantia de direitos da criança e do adolescente, como Conselho Tutelar Municipal.

[...] aos finais de semana, o patrulhamento da polícia militar é intensificado com soldados advindos de outros Municípios, visto que o número de soldados e carros disponíveis são insuficientes para atender à demanda. ${ }^{39}$

38 FERREIRA, Silvia Aline Silva. Contribuição ao Estudo dos Dilemas e Impactos das Unidades Prisionais do Pontal do Paranapanema: um Estudo de Caso do Município de Marabá. p. 118.

39 FERREIRA, Silvia Aline Silva. Contribuição ao Estudo dos Dilemas e Impactos das Unidades Prisionais do Pontal do Paranapanema: um Estudo de Caso do Município de Marabá. p. 118. 
GRANZOTTO, Eduardo; PERTILLE, Marcelo Bauer; PERTILLE, Thais Silveira. Externalidades na instalação de estabelecimentos prisionais nos municípios brasileiros: propostas legislativas para o atendimento do princípio da eficiência econômico-social. Revista Eletrônica Direito e Política, Programa de Pós-Graduação Stricto Sensu em Ciência Jurídica da UNIVALI, Itajaí, v.16, n.2, 20 quadrimestre de 2021. Disponível em: www.univali.br/direitoepolitica - ISSN 1980-7791.

Além disso, têm-se como externalidade negativa os impactos ambientais e paisagísticos. O funcionamento de um estabelecimento penal, por si só, implica no crescimento da produção de esgoto e de lixo, também alterando o cenário urbano. A arquitetura carcerária dificilmente é posta em sintonia com o seu entorno, criando significativa mudança na paisagem. Nesse sentido, Raul Victor do Nascimento afirma que:

Há, ao lado da PEP [Penitenciária Estadual de Paramirim Rio Grande do Norte], um pequeno veio de água que provavelmente desagua no Rio Pitimbu, e que estava, graças aos dejetos da prisão, completamente poluído. Do pequeno riacho, povoado por moscas e urubus, emanava um mau cheiro intenso e desagradável. ${ }^{40}$

Quanto ao meio ambiente natural, a falta de sustentabilidade pode limitar o crescimento econômico em geral. Considerada também a possibilidade de exaustão de insumos ambientais - seja pelo uso ou pela degradação da fonte -, haja vista o número de internos e o aumento populacional, poder-se-ia pensar até na elevação de preços e, em consequência, na limitação de uso.

Todavia, nesse particular, vale advertir que é característica do próprio mercado que não sinalize cenários de escassez, fator que acaba motivando o uso desregrado do ambiente, inclusive. ${ }^{41}$ Razão pela qual essas externalidades ambientais precisam ser consideradas não só em benefício da sociedade presente, como também das gerações futuras. ${ }^{42}$

Ainda, é preciso destacar entre as externalidades negativas a desvalorização imobiliária. Isso porque a instalação de unidades prisionais tende a diminuir a demanda por imóveis em seu entorno. Isso demonstra a necessidade de análise sistêmica dos impactos, haja vista que, em grande medida, a desvalorização se dá por problema já nominado anteriormente: constante sensação de insegurança e o estigma social.

\footnotetext{
40 NASCIMENTO, Raul Victor Rodrigues do. Estudo de Impacto de Vizinhança e a Construção de Novos Estabelecimentos Penais: delineando uma relação. p. 187. 41 WEYDMANN, Celso Leonardo. Externalidades e mudanças da regulamentação ambiental para a suinocultura norte-americana: é possível no caso brasileiro?. pp. 287-305.

42 LEITE, José Rubens Morato (coord.). Manual de Direito Ambiental. São Paulo: Saraiva, 2015. p. 93.
} 
GRANZOTTO, Eduardo; PERTILLE, Marcelo Bauer; PERTILLE, Thais Silveira. Externalidades na instalação de estabelecimentos prisionais nos municípios brasileiros: propostas legislativas para o atendimento do princípio da eficiência econômico-social. Revista Eletrônica Direito e Política, Programa de Pós-Graduação Stricto Sensu em Ciência Jurídica da UNIVALI, Itajaí, v.16, n.2, 20 quadrimestre de 2021. Disponível em: www.univali.br/direitoepolitica - ISSN 1980-7791.

Em recente matéria do jornal Estado de S. Paulo intitulada "Saiba quais são os fatores que podem depreciar o valor do imóvel", a proximidade de presídios foi apontada entre os oito maiores fatores de desvalorização de um imóvel no Brasil:

Não é segredo que o investimento em imóveis é considerado um bom negócio. No entanto, é preciso se atentar a alguns detalhes no processo de aquisição para evitar prejuízos no momento de revender ou colocar para alugar. Para ajudar a identificar as características que podem rebaixar o valor de mercado, consultamos o CEO da Casafy, portal de negócios imobiliários, Renato Orfaly.

$[\ldots]$

8 - Presídios

O que deveria ser sinônimo de segurança, não é visto dessa forma pelo mercado imobiliário. A possibilidade de conviver ao lado de um presídio afugenta as pessoas, não só pela confusão causada pela movimentação habitual de criminosos e policiais fortemente armados, mas também por eventualidades, como rebeliões ou fugas. ${ }^{43}$

Diante de tudo que foi levantado até aqui, vê-se que a construção de estabelecimentos penais tende a causar mais externalidades negativas do que positivas aos Municípios. É possível, no entanto, alterar a legislação federal vigente como forma de minimizar esses impactos, compensando consequências.

Nesse sentido, vale lembrar de Eggertsson, que tratando de externalidades negativas, afirmou: "a regulamentação, ao depender fundamentalmente do Estado, é a melhor forma para delinear os direitos"44.

\footnotetext{
43 ESTADO DE S. PAULO. Saiba quais são os fatores que podem depreciar o valor do imóvel, Matéria publicada no dia 16.8.2019. Disponível em: https://imoveis.estadao.com.br/compra/saibaquais-sao-os-fatores-que-podem-depreciar-o-valor-do-imovel/, acessado em 27.3.2021.

${ }^{44}$ EGGERTSOON, T. Economic behavior and institutions New York: Cambridge University Press. 1994. p. 120.
} 
GRANZOTTO, Eduardo; PERTILLE, Marcelo Bauer; PERTILLE, Thais Silveira. Externalidades na instalação de estabelecimentos prisionais nos municípios brasileiros: propostas legislativas para o atendimento do princípio da eficiência econômico-social. Revista Eletrônica Direito e Política, Programa de Pós-Graduação Stricto Sensu em Ciência Jurídica da UNIVALI, Itajaí, v.16, n.2, $2^{\circ}$ quadrimestre de 2021. Disponível em: www.univali.br/direitoepolitica - ISSN 1980-7791.

\section{SUGESTÕES LEGISLATIVAS PARA CONCRETIZAÇÃO DO PRINCÍPIO DA EFICIÊNCIA ECONÔMICO-FINANCEIRA}

O princípio da eficiência foi integrado à Constituição Federal brasileira com a Emenda Constitucional número 19, de 1998. A eficiência foi, então, incluída aos princípios da Administração Pública no art. 37. Contudo, não se pode afirmar que representou expressiva novidade, considerando-se que a eficiência da gestão orçamentária já era ponto tratado pela Carta Magna em sua versão original. ${ }^{45}$

Relacionando a perspectiva que interessa a este estudo, Gabardo preleciona que o princípio da eficiência pode ser tomado sob três aspectos: a) eficiência econômica stricto sensu (relação entre custos e valor dos resultados); b) eficiência econômica consignativa (distribuição ótima dos recursos disponíveis); c) eficiência econômica produtiva (maior rendimento na utilização dos recursos ou minimização dos custos). ${ }^{46}$ Para a análise econômica do Direito a preocupação acerca do princípio atingirá à "comparação entre o que foi produzido e o que poderia ter sido produzido com a utilização dos mesmos recursos" ${ }^{47}$.

Porém, o Direito não pode ser tomado de forma a satisfazer expectativas quantitativas estritamente. Especialmente por ter como base ode constitucional ao bem-estar social, a regra tem fundamentos e valores que precisam ser contemplados.

Como explicam Gonçalves e Stelzer, a Ciência Econômica tem o condão de conferir ao Direito eficácia na tomada de decisão normativo-jurídica ao indicar pelo cálculo econométrico variáveis próprias de inclusão social. Os autores identificam a Teoria do Princípio da Eficiência Econômico-Social (PEES) como a possibilidade de interação econômico-jurídica inovadora e socialmente inclusora. Trata-se de orientação "para a realização dos Direitos individuais e sociais de

\footnotetext{
45 FERREIRA, Carlo Lélio Lauria; SANTIAGO, Nestor Eduardo Araruna. O custo do encarceramento no Brasil sob a ótica da análise econômica do Direito. Revista Digital Constituição e Garantia de Direitos. Vol. 11, no 1. 2018.

46 GABARDO, Emerson. Princípio constitucional da eficiência administrativa. São Paulo. Dialética, 2002, p. 30.

47 FERREIRA, Carlo Lélio Lauria; SANTIAGO, Nestor Eduardo Araruna. O custo do encarceramento no Brasil sob a ótica da análise econômica do Direito. p. 209.
} 
GRANZOTTO, Eduardo; PERTILLE, Marcelo Bauer; PERTILLE, Thais Silveira. Externalidades na instalação de estabelecimentos prisionais nos municípios brasileiros: propostas legislativas para o atendimento do princípio da eficiência econômico-social. Revista Eletrônica Direito e Política, Programa de Pós-Graduação Stricto Sensu em Ciência Jurídica da UNIVALI, Itajaí, v.16, n.2, 20 quadrimestre de 2021. Disponível em: www.univali.br/direitoepolitica - ISSN 1980-7791.

forma eficaz e eficiente; permitindo racionalidade e humanização para a norma positivada $(\ldots)^{\prime \prime} .48$

O PEES, por conseguinte, coaduna a necessária análise da importância de estabelecimentos penais levando em conta a concretização dos fins da pena e a promoção da justiça não só para aqueles albergados pelo sistema penal, mas também para as localidades que receberão a instalação dessas instituições. $O$ princípio emana, principalmente, das teorias de três autores: Vilfredo Pareto (1984), Nicholas Kaldor (1939) e de John Hicks (1939). ${ }^{49}$

Nesse sentido, o referencial intitulado "ótimo de Pareto" seria o resultado dos ajustes que implicam melhoria cuja situação não pode mais evoluir em benefícios, ou seja, quando se atinge o estado considerado ótimo. Sob aspecto social, significa "melhorar as condições de um agente ou a utilidade que este obtém em sociedade, sem prejudicar a situação ou utilidade de qualquer outro agente econômico ou sujeito de direito" ${ }^{\prime 50}$. Importante advertir que a teoria de Pareto coloca um ideal atingível, porém insuperável como meta.

O critério Kaldor Hicks, todavia, admite níveis acima de Pareto, desde que instrumentalizados arranjos colaborativos. ${ }^{51} \mathrm{Em}$ síntese, mesmo que a princípio algumas externalidades negativas precisem ser admitidas, ao final poderiam ser compensadas gerando maior eficiência na distribuição de recursos.

Assim é que se pode ir adiante mesmo na presença de algumas externalidades negativas. E aqui a importância do Direito ao oferecer condições para que se possa definir possibilidades dessa atuação, quando devem ser levados a efeito os limites e critérios de responsabilização jurídica. Justifica-se, então, a intersecção do Direito com critérios de ordem econômica, admitindo-se que o Princípio da

48 GONÇALVES, Everton das Neves e STELZER, Joana. O viés econômico do direito justo e eficiente: O princípio da eficiência econômico-social. Revista Jurídica do Unicuritiba, v. 3, n. 32, 2013. Pp. 128-162.

49 GONÇALVES, Everton das Neves e STELZER, Joana. O viés econômico do direito justo e eficiente: O princípio da eficiência econômico-social. p. 148.

50 GONÇALVES, Everton das Neves e STELZER, Joana. O viés econômico do direito justo e eficiente: $O$ princípio da eficiência econômico-social. p. 148.

${ }^{51}$ GONÇALVES, Everton das Neves e STELZER, Joana. O viés econômico do direito justo e eficiente: O princípio da eficiência econômico-social. p. 148. 
GRANZOTTO, Eduardo; PERTILLE, Marcelo Bauer; PERTILLE, Thais Silveira. Externalidades na instalação de estabelecimentos prisionais nos municípios brasileiros: propostas legislativas para o atendimento do princípio da eficiência econômico-social. Revista Eletrônica Direito e Política, Programa de Pós-Graduação Stricto Sensu em Ciência Jurídica da UNIVALI, Itajaí, v.16, n.2, 20 quadrimestre de 2021. Disponível em: www.univali.br/direitoepolitica - ISSN 1980-7791.

Eficiência Econômico Social (PEES) se converte na busca por eficiência sem que se perca de vista a proteção da dignidade da pessoa humana como fim.

Nesse arranjo, ter como mote o PEES é considerar que "se a análise econômica de custos e benefícios não considera critérios distributivos e, preconizando maiores lucros para um grupo, submete outro a carências" ${ }^{52}$. Gonçalves e Stelzer dão luz ao ponto, considerando que na busca da eliminação do desequilíbrio social, a regulamentação deve determinar a obrigação de compensação dos desfavorecidos ou destituídos de suas prerrogativas em função da adoção de possibilidades eficientes. Nessa perspectiva:

(...) denomina-se colapso regulatório quando a regulamentação é ineficiente para resolver os problemas para a qual se destina, ou ainda quando gera problemas não intencionais na eficiência dos agentes. Visando evitar o colapso, o regulador deve ter independência, qualificação técnica e recursos materiais. ${ }^{53}$

A lógica importada da Economia, mas regrada pelo Direito, será a de maximizar os resultados eliminando as externalidades por sua absorção no processo. Temse aqui o ponto de encontro ao tema proposto neste estudo, eis que a mitigação das externalidades negativas causadas aos Municípios pela instalação de estabelecimentos penais é possível de diversas formas, possibilitando a concretização do PEES.

Nesta etapa, dar-se-á atenção a dois documentos que podem ser considerados essenciais e prioritários para que se efetivem as mudanças necessárias na consecução do PEES diante das discussões acerca da instalação de novas unidade penais: a) a alteração da Lei de Execução Penal (Lei no 7.210, de 11 de julho de 1984$)^{54}$ para tornar obrigatória a realização de Estudos de Impacto de Vizinhança antes de qualquer medida que pretenda a ocupação territorial; e b) a alteração da lei que dispõe sobre o Fundo de Participação do Municípios (Lei

52 GONÇALVES, Everton das Neves e STELZER, Joana. O viés econômico do direito justo e eficiente: O princípio da eficiência econômico-social. p. 141.

53 SANTANA, E. A. (1995). Teoria do agente-principal, regulação e performance da indústria de energia elétrica no Brasil. Anais do XXIII Encontro Nacional de Economia, vol. 1. Rio de Janeiro: Associação Nacional dos Cursos de Pós-Graduação em Economia (ANPEC), p. 403-421.

${ }^{54}$ BRASIL. Lei no 7.210, de 11 de julho de 1984 Institui a Lei de Execução Penal. Disponível em: http://www.planalto.gov.br/ccivil_03/leis/l7210.htm, acessado em 27.3.2021. 
GRANZOTTO, Eduardo; PERTILLE, Marcelo Bauer; PERTILLE, Thais Silveira. Externalidades na instalação de estabelecimentos prisionais nos municípios brasileiros: propostas legislativas para o atendimento do princípio da eficiência econômico-social. Revista Eletrônica Direito e Política, Programa de Pós-Graduação Stricto Sensu em Ciência Jurídica da UNIVALI, Itajaí, v.16, n.2, 20 quadrimestre de 2021. Disponível em: www.univali.br/direitoepolitica - ISSN 1980-7791.

Complementar no 91, de 22 de dezembro de 1997), para aumentar o coeficiente de arrecadação do Município que tenha uma unidade penal em seus domínios.

Iniciando pelo Estudo de Impacto de Vizinhança (EIV), explica-se que se constitui em um instrumento urbanístico previsto nos arts. 36, 37 e 38 do Estatuto das Cidades (Lei no 10.257, de 10 de julho de 2001) ${ }^{55}$ :

Art. 36. Lei municipal definirá os empreendimentos e atividades privados ou públicos em área urbana que dependerão de elaboração de estudo prévio de impacto de vizinhança (EIV) para obter as licenças ou autorizações de construção, ampliação ou funcionamento a cargo do Poder Público municipal.

Art. 37. O EIV será executado de forma a contemplar os efeitos positivos e negativos do empreendimento ou atividade quanto à qualidade de vida da população residente na área e suas proximidades, incluindo a análise, no mínimo, das seguintes questões:

I - adensamento populacional;

II - equipamentos urbanos e comunitários;

III - uso e ocupação do solo;

IV - valorização imobiliária;

V - geração de tráfego e demanda por transporte público;

VI - ventilação e iluminação;

VII - paisagem urbana e patrimônio natural e cultural.

Parágrafo único. Dar-se-á publicidade aos documentos integrantes do EIV, que ficarão disponíveis para consulta, no órgão competente do Poder Público municipal, por qualquer interessado.

Art. 38. A elaboração do EIV não substitui a elaboração e a aprovação de estudo prévio de impacto ambiental (EIA), requeridas nos termos da legislação ambiental.

55 BRASIL. Lei no 10.257, de 10 de julho de 2001. Regulamenta os arts. 182 e 183 da Constituição Federal, estabelece diretrizes gerais da política urbana e dá outras providências. Disponível em: http://www.planalto.gov.br/ccivil_03/leis/leis_2001/l10257.htm, acessado em 27.3.2021. 
GRANZOTTO, Eduardo; PERTILLE, Marcelo Bauer; PERTILLE, Thais Silveira. Externalidades na instalação de estabelecimentos prisionais nos municípios brasileiros: propostas legislativas para o atendimento do princípio da eficiência econômico-social. Revista Eletrônica Direito e Política, Programa de Pós-Graduação Stricto Sensu em Ciência Jurídica da UNIVALI, Itajaí, v.16, n.2, $2^{\circ}$ quadrimestre de 2021. Disponível em: www.univali.br/direitoepolitica - ISSN 1980-7791.

O EIV tem natureza técnica e preza pelo interesse coletivo por meio da efetivação dos princípios da função social da propriedade e da função social da cidade, com melhor aproveitamento de áreas urbanas. ${ }^{56}$ Ou seja, serve justamente para detalhar os impactos positivos e negativos que uma atividade gera ao seu entorno. Uma vez conhecidos esses impactos, é possível traçar diretrizes que atenuem os efeitos negativos, proporcionando melhores condições de habitabilidade, conforto e segurança aos munícipes.

Ocorre que, de acordo com a redação do art. 36, são os próprios Municípios que definem, por lei local, quais serão os empreendimentos e atividades que dependerão de elaboração previa de EIV. No entanto, embora tenha competência para tanto, é raro o município que estabeleça por lei local a obrigatoriedade de elaboração de EIV antes da instalação de unidades penais.

Uma solução, portanto, seria estabelecer, por lei federal, a obrigatoriedade desse estudo prévio em caso de instalação de novas unidades penais. $O$ instrumento correto para isso seria uma alteração da Lei de Execução Penal (Lei no 7.210, de 11 de julho de 1984), preferencialmente nas "Disposições Gerais" do "Título IV Dos Estabelecimentos Penais". Uma sugestão seria a inclusão de um artigo determinando que:

A instalação de estabelecimentos penais em Municípios está condicionada à elaboração de Estudo de Impacto de Vizinhança (EIV), que deverá analisar, além dos requisitos previstos no art. 37 da Lei no 10.257, de 10 de julho de 2001, questões socioeconômicas e de segurança, sem prejuízo dos estudos ambientais cabíveis.

O levantamento prévio das externalidades da instalação de uma unidade penal em um município, conforme aqui sugerido, é peça fundamental para que os Estados e, até mesmo a União, possam atuar nas políticas públicas necessárias para mitigar impactos negativos.

Quanto à alteração da lei que dispõe sobre o Fundo de Participação do Municípios, a intenção é a de atribuir mais recursos para as administrações locais

${ }^{56}$ SILVA, José Afonso da. Direito Urbanístico Brasileiro. São Paulo: Malheiros, 2012. 
GRANZOTTO, Eduardo; PERTILLE, Marcelo Bauer; PERTILLE, Thais Silveira. Externalidades na instalação de estabelecimentos prisionais nos municípios brasileiros: propostas legislativas para o atendimento do princípio da eficiência econômico-social. Revista Eletrônica Direito e Política, Programa de Pós-Graduação Stricto Sensu em Ciência Jurídica da UNIVALI, Itajaí, v.16, n.2, 20 quadrimestre de 2021. Disponível em: www.univali.br/direitoepolitica - ISSN 1980-7791.

a fim de que tenham maior capacidade de investimentos em políticas públicas. Tal possibilidade contemplaria exemplarmente o primado do PEES eis que:

maximizadora de resultados esperados quando da
adjudicação de direitos entre os agentes, ou quando
determinante de obrigações - não devendo olvidar a
consideração, no cálculo econométrico, das variáveis de
cunho social e temporal que, corretamente valoradas,
devem ser internalizadas de forma que a relação de custo e
benefício demonstre a realidade das utilidades auferidas
quando se sacrificando determinados bens e serviços de
outrem, ainda, considerado o maior número possível ou a
totalidade dos agentes envolvidos e possibilitada a
eliminação das externalidades para a sociedade presente e
futura. ${ }^{57}$

O instrumento correto para isso, sugere-se, seria a inclusão de um novo parágrafo ao art. $1^{0}$ da Lei Complementar no 91, de 22 de dezembro de 1997, que dispõe sobre a fixação dos coeficientes do Fundo de Participação dos Municípios. A alteração poderia conter a seguinte redação:

O município que for sede de estabelecimento penal deve ser enquadrado no coeficiente imediatamente superior ao que teria direito, independentemente do número de habitantes.

Percebe-se, portanto, que pautado no princípio da eficiência econômico-social o Direito consegue, por meio de uma análise econômica, corresponder às exigências para que possa participar ativamente na prevenção de danos e na delimitação de responsabilidades frente às externalidades identificadas como negativas. A importância dessa constatação se dá na garantia de que o Direito, absorvendo contextos teóricos incialmente estranhos às suas dogmáticas, esteja adaptado às demandas contemporâneas, mostrando-se instrumento útil e indispensável na regulação normativa e nos debates teóricos de interesses sociais.

${ }^{57}$ GONÇALVES, Everton das Neves e STELZER, Joana. O viés econômico do direito justo e eficiente: $O$ princípio da eficiência econômico-social. p. 141. 
GRANZOTTO, Eduardo; PERTILLE, Marcelo Bauer; PERTILLE, Thais Silveira. Externalidades na instalação de estabelecimentos prisionais nos municípios brasileiros: propostas legislativas para 0 atendimento do princípio da eficiência econômico-social. Revista Eletrônica Direito e Política, Programa de Pós-Graduação Stricto Sensu em Ciência Jurídica da UNIVALI, Itajaí, v.16, n.2, 20 quadrimestre de 2021. Disponível em: www.univali.br/direitoepolitica - ISSN 1980-7791.

\section{CONSIDERAÇÕES FINAIS}

O Brasil é um dos países que mais encarceram no mundo em números absolutos, o que, diante da falta de estrutura física, colabora para uma superlotação que convive com déficit de mais 200 mil vagas. Além de outras políticas públicas, a instalação de novos estabelecimentos penais é uma medida que necessita ser considerada. Ocorre que embora essa responsabilidade seja da União e dos Estados, são os Municípios que sofrem os maiores impactos. Esses, lidos a partir de análise econômica do Direito, foram identificados aqui enquanto externalidades.

As externalidades podem ser positivas, com o estímulo da economia local e o aumento da arrecadação de recursos por meio do FPM, mas também negativas, operando aumento da insegurança, da degradação social, da desvalorização imobiliária e dos prejuízos ambientais e paisagísticos. Essas consequências podem variar decisivamente a depender das características de cada município. Ainda assim, em geral, como visto no decorrer do estudo, as externalidades negativas tendem a ser maiores que as positivas, o que geram resistências por parte das administrações locais e seus munícipes.

Com a intenção de propor argumentos capazes de contornar as externalidades negativas, sobretudo em razão da premente necessidade de novas vagas para o sistema penitenciário, invocou-se o princípio da eficiência econômico-social. Assim é que o estudo se destinou a investigar se a análise econômica do Direito teria condições de colaborar com o impasse estabelecido em torno da insatisfação por parte de administrações municipais em receber essas unidades.

Sob o enfoque econômico-social, admitido enquanto a orquestração dos recursos disponíveis para o atingimento dos melhores resultados possíveis, compreendidos à luz do fundamento ético-político do Estado (fruição das diversas políticas para a dignidade humana), concluiu-se ser indispensável, a partir dos estudos de Kaldor Hicks, que haja políticas públicas de incentivo e mitigação de externalidades negativas identificadas. 
GRANZOTTO, Eduardo; PERTILLE, Marcelo Bauer; PERTILLE, Thais Silveira. Externalidades na instalação de estabelecimentos prisionais nos municípios brasileiros: propostas legislativas para o atendimento do princípio da eficiência econômico-social. Revista Eletrônica Direito e Política, Programa de Pós-Graduação Stricto Sensu em Ciência Jurídica da UNIVALI, Itajaí, v.16, n.2, $2^{\circ}$ quadrimestre de 2021. Disponível em: www.univali.br/direitoepolitica - ISSN 1980-7791.

Para tanto, entendeu-se possível mitigar efeitos por meio de pontuais alterações legislativas. Considerando as competências federais, propôs-se: (i) a alteração da Lei de Execução Penal (Lei no 7.210, de 11 de julho de 1984) para tornar obrigatória a realização de Estudos de Impacto de Vizinhança antes da instalação de unidades penais; (ii) a alteração da lei que dispõe sobre o Fundo de Participação do Municípios (Lei Complementar no 91, de 22 de dezembro de 1997) para aumentar o coeficiente de arrecadação do Município que tenha uma unidade penal em seu território.

Diante disso, vislumbrou-se que institutos desenvolvidos por meio da análise econômica do Direito apresentam condição de colaborar com o tema, haja vista se relacionarem justamente com ponto decisivo para a questão, qual seja, a escassez de recursos diante de objetivos indispensáveis.

Vale lembrar, por fim, que as medidas propostas devem ser lidas sob aspectos gerais, em contexto exemplificativo, sempre dependentes das particularidades de realidades locais. Ainda assim, insiste-se que diante da importância do tema, mostra-se fundamental que os ambientes acadêmico e político considerem, dentro de seus focos de atuação, argumentos capazes de racionalizar soluções.

\section{REFERÊNCIAS DAS FONTES CITADAS}

AGÊNCIA SENADO. Desconfiança e preconceito da sociedade dificultam ressocialização de presos. 2017. Disponível em: https://www12.senado.leg.br/noticias/especiais/especial-cidadania/desconfiancae-preconceito-da-sociedade-dificultam-ressocializacao-de-presos Acesso em: 09/07/2021.

ALVAREZ, Alejandro. Análise Econômica do Direito: contribuições e desmistificações. Disponível em: <http://direitoestadosociedade.jur.pucrio.br/media/Bugallo_n29.pdf> Acesso em: 4 junho. 2021.

ANDRADE, Vera Regina. A ilusão de segurança jurídica: do controle da violência à violência do controle. Livraria do Advogado: Porto Alegre, 1997.

BUENO, Samira; LIMA, Renato Sérgio (coord.). Anuário brasileiro de segurança pública. 2020. Disponível em: https://forumseguranca.org.br/wp- 
GRANZOTTO, Eduardo; PERTILLE, Marcelo Bauer; PERTILLE, Thais Silveira. Externalidades na instalação de estabelecimentos prisionais nos municípios brasileiros: propostas legislativas para o atendimento do princípio da eficiência econômico-social. Revista Eletrônica Direito e Política, Programa de Pós-Graduação Stricto Sensu em Ciência Jurídica da UNIVALI, Itajaí, v.16, n.2, $2^{\circ}$ quadrimestre de 2021. Disponível em: www.univali.br/direitoepolitica - ISSN 1980-7791.

content/uploads/2020/10/anuario-14-2020-v1-interativo.pdf Acesso em 08.07.2021.

BRASIL. Lei no 7.210, de 11 de julho de 1984 Institui a Lei de Execução Penal. Disponível em: http://www.planalto.gov.br/ccivil_03/leis/l7210.htm, acessado em 27.3.2021.

BRASIL. Lei no 10.257, de 10 de julho de 2001. Regulamenta os arts. 182 e 183 da Constituição Federal, estabelece diretrizes gerais da política urbana e dá outras providências. Disponível em: http://www.planalto.gov.br/ccivil_03/leis/leis_2001//10257.htm, acessado em 27.3.2021.

BRASIL. Supremo Tribunal Federal. Arguição de Descumprimento de Preceito Fundamental n. 347/DF. Relator: ministro Marco Aurélio. Brasília, 9 de setembro de 2015.

CÂMARA DOS DEPUTADOS. ONU faz alerta sobre presídios no Brasil e apoia desencarceramento por causa da pandemia; presidente da CDHM endossou iniciativa em março. 2020. Disponível em: https://www2.camara.leg.br/atividade-legislativa/comissoes/comissoespermanentes/cdhm/noticias/onu-faz-alerta-sobre-presidios-no-brasil-e-apoiadesencarceramento-por-causa-da-pandemia-presidente-da-cdhm-endossouiniciativa-em-marco Acesso em: 09/07/2021.

CESCON, Flávia R. P.; BAENINGER, Rosana. Cidades Carcerárias: Migração e Presídios em Regiões de São Paulo Trabalho apresentado no XVII Encontro Nacional de Estudos Populacionais, realizado em Caxambu - MG - Brasil, de 20 a 24 de setembro de 2010. Disponível em: http://www.abep.org.br/ abeporgb/publicacoes/index.php/anais/article/viewFile /2328/2282, acesso em 27.3.2021.

CNJ. Sítio eletrônico do Geopresídios. 2021. Disponível em: https://www.cnj.jus.br/inspecao_penal/mapa.php, acessado em 27.3.2021.

COASE, Ronald. O problema do custo social. The Latin American and Caribbean Journal of Legal Studies. Volume 3, Issue 1. Article 9. University of Chicago. 2008.

CONSELHO NACIONAL DO MINISTÉRIO PÚBLICO. Sistema Prisional em Números. $2020 . \quad$ Disponível em: https://www.cnmp.mp.br/portal/relatoriosbi/sistema-prisional-em-numeros. Acesso em: 12/07/2021.

EGGERTSOON, T. Economic behavior and institutions New York: Cambridge University Press. 1994. 
GRANZOTTO, Eduardo; PERTILLE, Marcelo Bauer; PERTILLE, Thais Silveira. Externalidades na instalação de estabelecimentos prisionais nos municípios brasileiros: propostas legislativas para o atendimento do princípio da eficiência econômico-social. Revista Eletrônica Direito e Política, Programa de Pós-Graduação Stricto Sensu em Ciência Jurídica da UNIVALI, Itajaí, v.16, n.2, $2^{\circ}$ quadrimestre de 2021. Disponível em: www.univali.br/direitoepolitica - ISSN 1980-7791.

ESTADO DE S. PAULO. Saiba quais são os fatores que podem depreciar o valor do imóvel, Matéria publicada no dia 16.8.2019. Disponível em: https://imoveis.estadao.com.br/compra/saiba-quais-sao-os-fatores-que-podemdepreciar-o-valor-do-imovel/, acessado em 27.3.2021.

FERREIRA, Silvia Aline Silva. Contribuição ao Estudo dos Dilemas e Impactos das Unidades Prisionais do Pontal do Paranapanema: um Estudo de Caso do Município de Marabá. Tese de Mestrado defendida em 7.12.2017, na Universidade do Oeste Paulista - UNOESTE. Disponível em: http://bdtd.unoeste.br:8080/jspui/handle/jspui/1075, acesso em 27.3.2021.

FERREIRA, Carlo Lélio Lauria; SANTIAGO, Nestor Eduardo Araruna. O custo do encarceramento no Brasil sob a ótica da análise econômica do Direito. Revista Digital Constituição e Garantia de Direitos. Vol. 11, nº 1. 2018.

GABARDO, Emerson. Princípio constitucional da eficiência administrativa. São Paulo. Dialética, 2002

G1. Monitor da Violência. 2021. Disponível em: https://especiais.g1.globo.com/monitor-da-violencia/2021/raio-x-do-sistemaprisional/ Acesso em: 09/07/2021.

GONÇALVES, Everton das Neves e STELZER, Joana. O viés econômico do direito justo e eficiente: O princípio da eficiência econômico-social. Revista Jurídica do Unicuritiba, v. 3, n. 32, 2013.

LEITE, José Rubens Morato (coord.). Manual de Direito Ambiental. São Paulo: Saraiva, 2015.

MAGALHÃES, Breno Baía. O Estado de Coisas Inconstitucional na ADPF 347 e a sedução do Direito: o impacto da medida cautelar e a resposta dos poderes políticos. Revista Direito GV,v. 15, n. 2, 2019, e1916. Doi: http://dx.doi.org/10.1590/2317-6172201916.

MARIANO, Jeferson; BARCELLOS, Lívia. As estratégias de gestão dos municípios brasileiros em cenário de crise econômica. Élisée, Rev. Geo. UEG - Porangatu, v.5, n.2, p.45-58, jul./dez. 2016.

MARTINS, Paulo Matos. Externalidades e custos externos: alguns conceitos quanto à sua avaliação e internalização no sector dos transportes. DEC/ISEL. 2004.

MENDES, Tânia R.. Impactos sociais e ambientais sofridos nos municípios com presídios, bem como alternativas de contrapartida do Estado para esses Municípios. Biblioteca Digital da Assembleia Legislativa de São Paulo. Disponível em: https://www.al.sp.gov.br/repositorio/bibliotecaDigital/377_arquivo.pdf, acessado em 27.3.2021. 
GRANZOTTO, Eduardo; PERTILLE, Marcelo Bauer; PERTILLE, Thais Silveira. Externalidades na instalação de estabelecimentos prisionais nos municípios brasileiros: propostas legislativas para o atendimento do princípio da eficiência econômico-social. Revista Eletrônica Direito e Política, Programa de Pós-Graduação Stricto Sensu em Ciência Jurídica da UNIVALI, Itajaí, v.16, n.2, 20 quadrimestre de 2021. Disponível em: www.univali.br/direitoepolitica - ISSN 1980-7791.

NASCIMENTO, Raul Victor Rodrigues do. Estudo de Impacto de Vizinhança e a Construção de Novos Estabelecimentos Penais: delineando uma relação. Revista Transgressões: Ciências Criminais em Debate, v.4, n.1, Maio 2016. Disponível em:https://periodicos.ufrn.br/transgressoes/article/view/9477/6843, acesso em 27.3.2021.

SANTANA, E. A. Teoria do agente-principal, regulação e performance da indústria de energia elétrica no Brasil. Anais do XXIII Encontro Nacional de Economia, vol. 1. Rio de Janeiro: Associação Nacional dos Cursos de PósGraduação em Economia (ANPEC). 1995.

SILVA, José Afonso da. Direito Urbanístico Brasileiro. São Paulo: Malheiros, 2012.

SILVESTRE, Giane. O rastro da Indústria Penal: A Interiorização Penitenciária e novo paradigma dos Municípios paulistas. Revista do Laboratório de Estudos da Violência e Segurança - Levis, n.1 (2008). Disponível em: http://www2.marilia.unesp.br/revistas/index.php/levs/article/view/767, acesso em 27.3.2021.

WEYDMANN, Celso Leonardo. Externalidades e mudanças da regulamentação ambiental para a suinocultura norte-americana: é possível no caso brasileiro? Revista de Economia e Sociologia Rural [online]. 2005, v. 43, n. 2. Acesso: 9/07/2021.

RECEBIDO EM: JUL/2021

APROVADO EM: AGO/2021 